${ }^{1}$ Department of Community Dentistry, Piracicaba Dental School, University of Campinas, Piracicaba, SP, Brazil

${ }^{2}$ Department of Orthodontics, Araras Dental School, University Center of Hermínio Ometto Foundation-FHO, Araras, SP, Brazil.
Corresponding author: Patrícia Rafaela dos Santos Av. Limeira, 901 - Vila Rezende. Piracicaba, SP - Brazil 13414-903. +5519999439853

e-mail: patriciarasantos@gmail.com

Received: September 12, 2019

Accepted: January 27, 2020

\section{Exploring the impact of oral health-related quality of life on the child's family structure}

Patrícia Rafaela dos Santos ${ }^{1, *}$, Felipe Alexandre de Souza², Diego Patrik Alves Carneiro ${ }^{2}$, Marcelo de Castro Meneghim', Silvia Amélia Scudeler Vedovello²

Aim: The aim of this study was to explore the impact of oral health-related quality of life (OHRQoL) on the child's family structure. Methods: A representative sample of 613 children from public preschools in a city in southeastern Brazil was included in this cross-sectional study. The sample was determined through probabilistic sampling in two stages (preschools and children). The outcome variable (Early Childhood Oral Health Impact Scale [ECOHIS]) was multi-categorized in children and family. Independent individual variables were sex, race, family income, parents'/ caregivers' level of education, family income, dental caries, and malocclusion. Initially, individual analyses were performed, relating the study variables to the outcome variables, estimating the raw odds ratio with the respective confidence intervals of $95 \%$. The variables with $p<0.20$ in the individual analyses were tested in the multiple logistic regression models, and those with $p<0.10$ remained in the model. Results: Impact on OHRQoL was reported by $40.9 \%$ of the children and $17 \%$ of their families. Children with low family income and caries experience had, respectively, 1.53 (95\% Cl: 1.00-2.32) $(p=0.0465)$ and 2.96 (95\% Cl: 1.81-4.84) $(p<0.0001)$ more chance of presenting negative impact on OHRQoL. Conclusion: The aspects that most affected the OHRQoL of child's family structure were low income and dental caries experience.

Keywords: Child, preschool. Dental caries. Malocclusion. Oral health. Child, preschool. Dental caries. Malocclusion. Oral health. 


\section{Introduction}

Oral health-related problems can play an important role in social acceptance, resulting in functional limitations, mainly in more severe cases ${ }^{1-4}$. Currently, it is known that assessment of oral health-related quality of life (OHRQoL) goes beyond traditional clinical measures to provide insight into the social and emotional experiences of individuals and their family and social context ${ }^{5}$.

Dental caries and malocclusion are the most common oral health-related problems in preschoolers and have been associated with a negative impact on OHRQoL $2,6,7$. Despite a significant reduction in the prevalence and severity of dental caries in Brazil in other age groups, $80 \%$ of affected teeth remain untreated in the primary dentition 7 . In this sense, caries disease, when left untreated, might lead to tooth loss, imposing functional limitations that have a negative impact on quality of life $\mathrm{e}^{6,8,9}$.

In addition, malocclusion is highly prevalent in populations at different stages of occlusal development ${ }^{10,11}$, varying according to ethnic group, age, and recording methods. However, severe malocclusion can affect the negative manner in which a person is perceived throughout his or her entire life. In this sense, studies have demonstrated the importance of detecting malocclusion in preschoolers as a prognostic action that allows for early treatment planning ${ }^{6}$.

Assuming that the clinical conditions do not exist in isolation, understanding the perception of family structure and exploring its impact on oral health aspects can help to assess treatment needs, prioritizing care and strategies ${ }^{2}$. Parental socioeconomic status and family structure can be significant predictors of children's OHRQoL because a positive family environment is known to be associated with better oral health behavior $^{12}$. On the other hand, these factors need to be better understood ${ }^{9}$ to know how the individual and socioeconomic characteristics influence OHRQoL. A recent study ${ }^{13}$ also suggested that contextual socioeconomic factors are more important than individual socioeconomic factors with regard to this outcome.

Individual health promotion strategies can be strengthened if also expanded to the community level ${ }^{13}$, which implies knowing the impact of oral conditions on the family structure. It is known that the family is fundamental for the maintenance of oral health, in an important age group for the future development of the individual. Thus, it is necessary to investigate how the clinical factors related to caries disease and occlusion, as well as contextual and behavioral factors, influence OHRQoL. The aim of this cross-sectional study was to explore the impact of OHRQoL on the child's family structure.

\section{Materials and methods}

This study received approval from the Human Research Ethics Committee of Brazil (CAAE: 24905113.0.0000.5385) and the Department of Education of the municipality. Parents/caregivers signed a statement of informed consent authorizing the participation of their children. 
A population-based cross-sectional study was conducted involving children aged 3-5 years enrolled at all public schools in the city of Araras, located in the state of São Paulo in southeast Brazil, from March to April 2017. Araras has an estimated population of 188,843 and a human development index of 0.78 .

All public schools ( $n=14$ ) with children in the target age range were included in the study, and probabilistic sampling was performed by conglomerates. The distribution of 3- to 5-year-old children in each region of Araras was determined from information provided by the municipal secretary of education. The sample was stratified according to administrative district and, in the first phase, schools were randomly selected. In the second phase, children were selected for the sample using a simple randomization procedure. Classrooms were randomly selected at the schools, and children were randomly selected from the classes. The sample size was calculated considering a confidence interval of $95 \%$, a test power of $80 \%$, and an odds ratio of 1.6 . The minimum sample size was defined as 604 children.

The inclusion criteria were children in primary dentition with no systemic problems (based on the reports of parents/caregivers) and no history of orthodontic treatment. Moreover, the parents/caregivers to be included in the study needed to have adequate reading and writing skills to answer the questionnaires. Thus, a total of 613 schoolchildren and their families participated in the study.

Data were collected through clinical oral examinations and interviews. One calibrated examiner carried out clinical examinations and recorded dental caries and malocclusion. Before the survey, the calibration process was performed in a group of 30 children who were 5 years old. Theoretical and clinical training and calibration exercises were arranged for a total of 36 hours under the supervision of one benchmark examiner $^{14}$. The mean Kappa values were above 0.81 and 0.92 for caries and malocclusion, respectively. A blinded dentist conducted the interviews.

The outcome variable was the Early Childhood Oral Health Impact Scale (ECOHIS), which was used to evaluate the impact of oral conditions on the OHRQoL of the child's family structure ${ }^{15}$. This questionnaire has been translated into Portuguese and validated for use on Brazilian populations (B-ECOHIS) ${ }^{16}$. Parents/caregivers were previously contacted and asked to attend a meeting at the preschool, during which they were informed about the objectives of the study.

The B-ECOHIS consists of 13 questions, divided into two sections: a child impact section with 4 domains (child symptoms, function, psychology, and self-image/social interaction domains) and a family impact section with 2 domains (parental distress and family function). Parents/caregivers answer the questions using a rating scale from 0 to 5 , where 0 = never, 1 = hardly ever, 2 = occasionally, 3 = often, 4 = very often, and $5=$ do not know. Total scores are calculated as the sum of the response codes, and the "do not know" answers are counted but excluded from the total ECOHIS score. Higher scores denote a greater oral health impact and poorer OHRQoL.

Sociodemographic data were collected to obtain an individual profile of the child's family structure (age, gender, parental education, and household income). Parental education was categorized considering the educational level of the mother and father 
and was dichotomized as $\leq 8$ years of study or $>8$ years of study. Household income was dichotomized based on the median (US\$350).

Caries were recorded using the dmf-t (mean number of decayed, missing, and filled primary teeth) in accordance with the $\mathrm{WHO}$ codes and criteria ${ }^{17}$. Caries experience was dichotomized as absent ( $d m f-t=$ zero) or present $(\mathrm{dmf}-\mathrm{t}>$ zero).

Malocclusion was classified according to the specific instrument for primary dentition, as recommended by the $\mathrm{WHO}^{17}$. The primary occlusion was examined according to the criteria of Foster and Hamilton ${ }^{18,19}$. Overjet was considered the relationship of incisors in the horizontal direction. No distance between maxillary and mandibular incisors was defined as normal overjet $(0 \mathrm{~mm})$. Increased overjet was recorded when the distance was $>2 \mathrm{~mm}$, and anterior crossbite was recorded when the distance was $<0 \mathrm{~mm}$. Normal overbite was defined when maxillary incisors overlapped mandibular incisors by $2 \mathrm{~mm}$. Overbite greater than $2 \mathrm{~mm}$ was designated deep overbite. Anterior crossbite was recorded when the mandibular incisors were observed in front of the maxillary incisors. Anterior open bite was recorded in the absence of contact between anterior teeth when posterior teeth were in occlusion. Posterior crossbite was recorded when maxillary primary molars were occluded in lingual relationship to mandibular primary molars in centric occlusion. The schoolchildren were diagnosed with absence of malocclusion when all the conditions were normal. When exhibiting at least one of the aforementioned conditions, they were classified as having absence of malocclusion'.

The study methodology is presented in Figure 1.

14 public schools

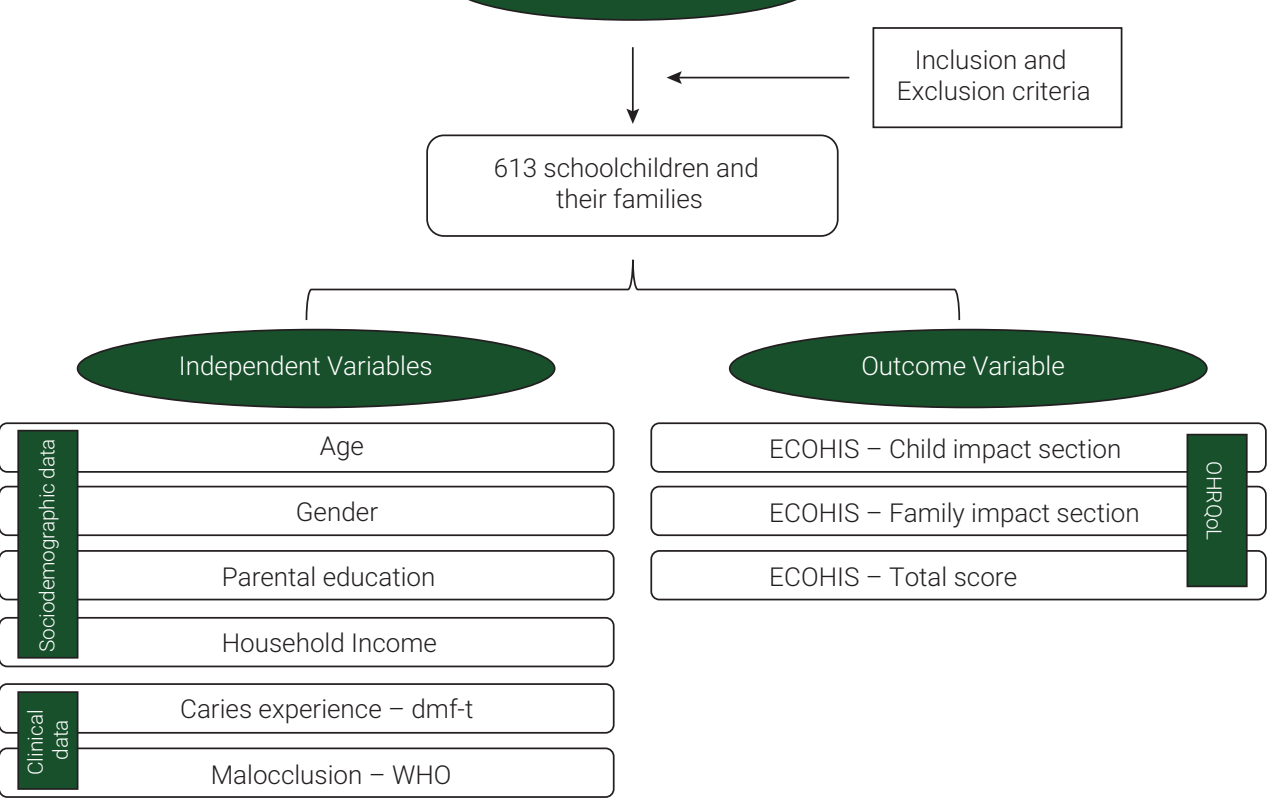

Figure 1. Methodological flowchart. 


\section{Statistical analysis}

Initially, individual analyses were performed relating the study variables (sex, race, income, father's and mother's educational level) as outcome variables (impact of oral health on quality of life-ECOHIS of the child, family, and total scores), estimating the raw odds ratios with the respective confidence intervals of $95 \%$. The variables with $p<0.20$ in the individual analyses were tested in the multiple logistic regression models, and those with $p<0.10$ remained in the model, estimating the adjusted odds ratio with the respective confidence intervals of $95 \%$. Analyses were performed in the $\mathrm{R}$ (R Foundation for Statistical Computing, Vienna, Austria) program.

\section{Results}

According to Table 1, of the schoolchildren evaluated, $40.9 \%$ presented impact of oral health on quality of life (ECOHIS $>0)$. Furthermore, children of families with income $\leq \mathrm{R} \$ 2000$ were observed to have 1.39 (95\% Cl: 0.97-2.00) ( $p=0.0696)$ times more chance of presenting impact of oral health on quality of life. Regarding the clinical conditions, 39.2\% presented malocclusion, and those with caries experience had 3.37 (95\% Cl: 2.29-4.97) ( $<$ 0.0001) times more chance of presenting impact of oral health on quality of life.

According to Table 2, 17\% of the families analyzed presented impact of oral health on quality of life $(E C O H I S>0)$. Families with income $\leq \mathrm{R} \$ 2000$ were observed to have $2.56(95 \% \mathrm{Cl}: 1.47-4.46)(p=0.0009)$ times more chance of presenting impact of oral health on quality of life. Families with children with caries experience had 4.46 (95\% Cl: 2.84-6.99) $(p<0.0001)$ times more chance of presenting impact of oral health on quality of life.

When the instrument was evaluated by means of the total scores, the ECOHIS of the child and family (Table 3), it was observed that $44.7 \%$ of the children and/or families presented impact of oral health on quality of life. Furthermore, families with income $\leq \mathrm{R} \$ 2000$ were observed to have $1.43(95 \% \mathrm{Cl}: 1.02-2.08)(p=0.0359)$ times more chance of (income) causing impact on the quality of life of children and families. Families with children with caries experience had 3.43 (95\% Cl: 2.31-5.08) $(p<0.0001)$ times more chance of presenting impact of oral health on quality of life.

\section{Discussion}

The aim of this study was to contextualize the association of socioeconomic and clinical factors with the impact of OHRQoL, from the perspective of family structure, because the clinical factors in isolation did not reflect the real impact of oral conditions on the individual's well-being. Clearly, despite the growing number of research studies on children's OHRQOL, there is a lack of studies related to family structure and support in the context of health ${ }^{20,21}$. 


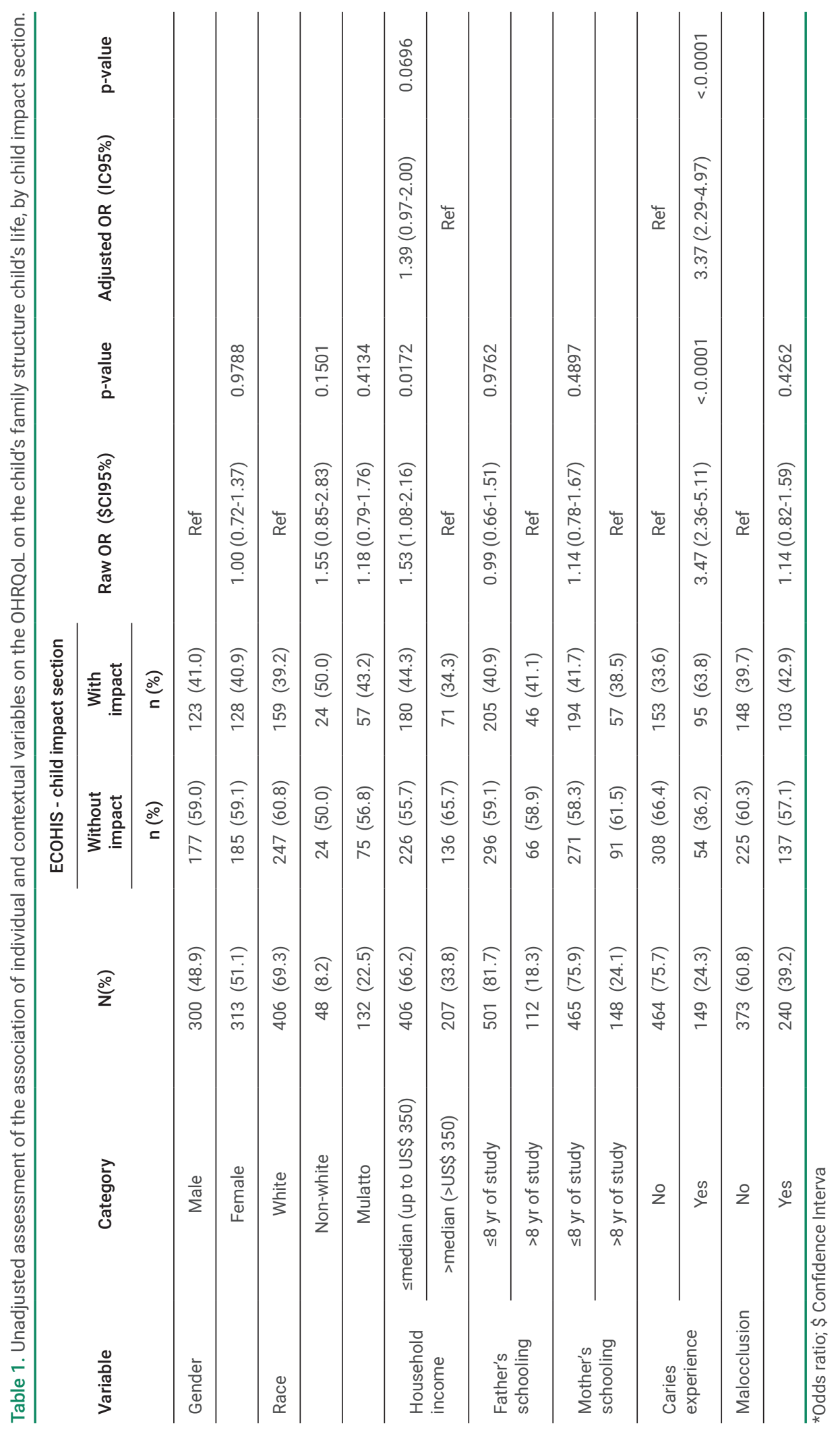




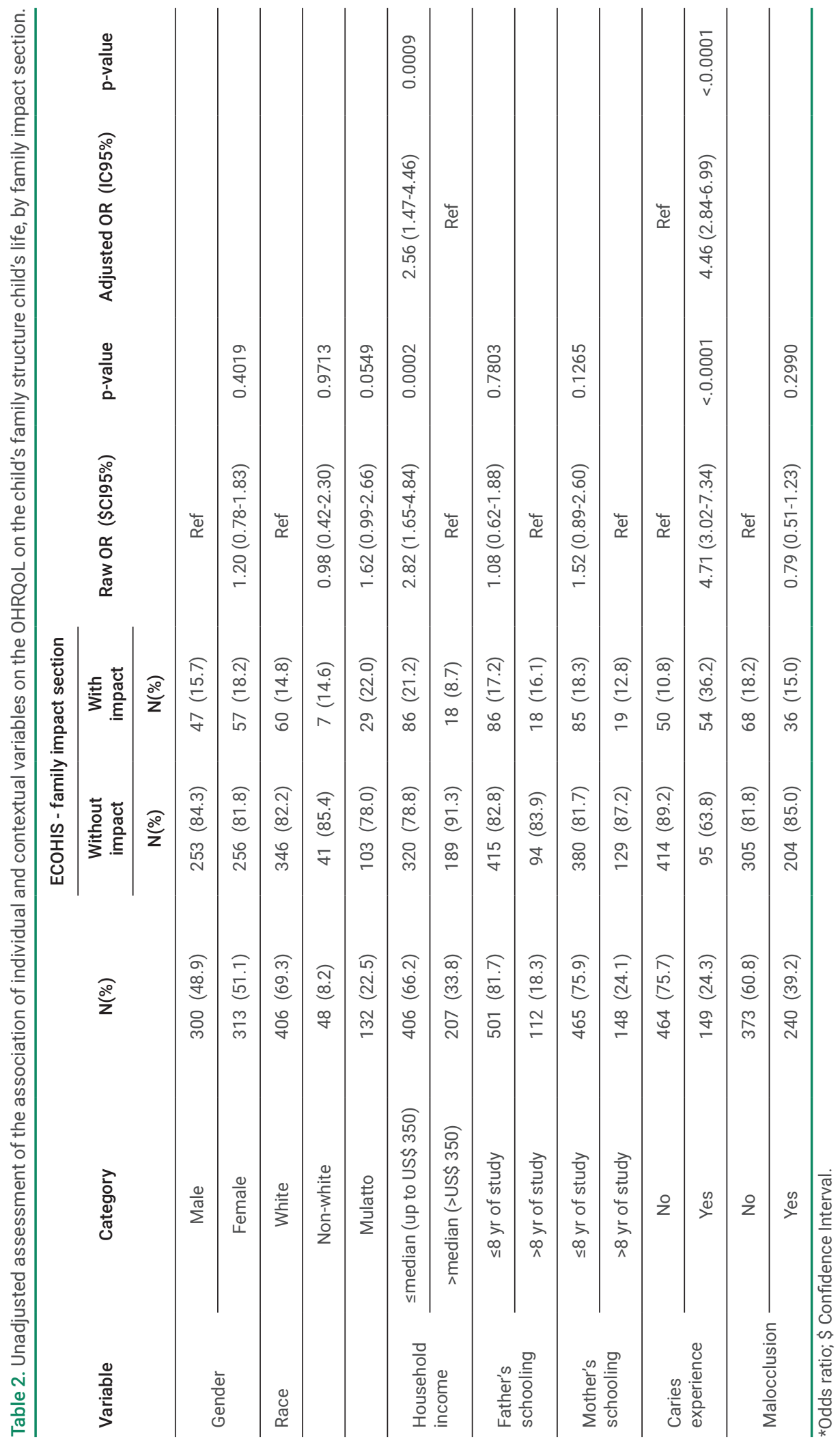




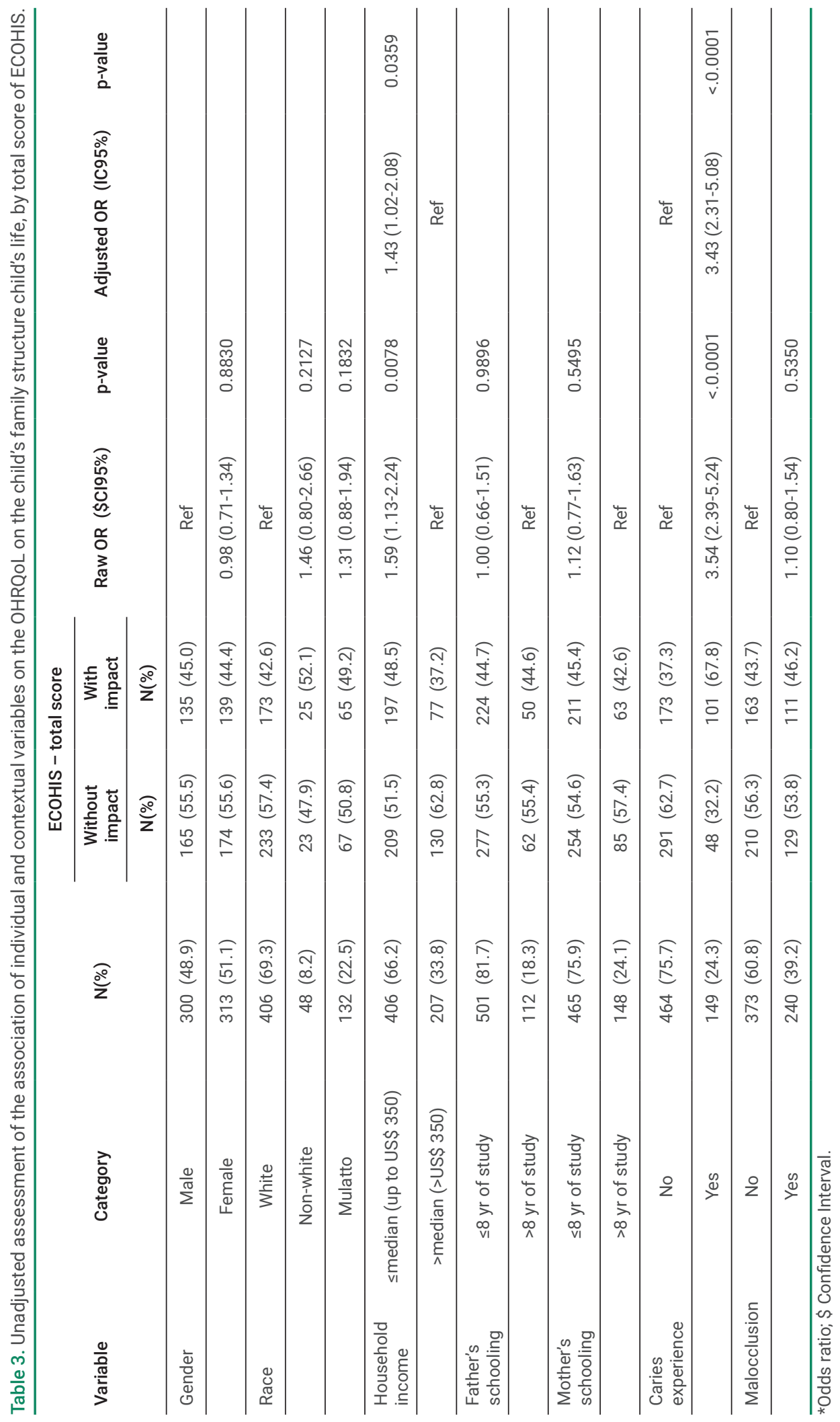


It should be noted that, as an evaluation tool, the ECOHIS allowed for broadening this analysis, leaving the binomial disease individual and including the family. Family structure is often referred to as the type of family in which a child is residing ${ }^{22}$, which justifies the choice of the ECOHIS as the outcome. Detecting the impact of social and economic factors in the extended family perspective, as commonly employed, allows us to discuss the impact that oral problems have on this nucleus ${ }^{23}$. Understanding this impact in the family nucleus allows us to suppose a greater adhesion of the families in the care of their children and to employ better directed strategies.

The socioeconomic condition affected the OHRQoL in all the contexts, in an increasing manner: of the child and, in a larger proportion, of the family. Of the aspects evaluated, income was the factor that negatively impacted the family, leading the authors to conclude that low income has more chance of influencing quality of life. Thus, the results corroborate the findings in the literature ${ }^{3-6,8,23}$, reaffirming that the child's oral health status is frequently associated with social dimensions. The discrepancies of the results observed in the literature were related to the methodological differences. In some studies, the impact of socioeconomic conditions on OHRQoL was evaluated only by the general score of the instrument, without determining the perspective of the child's family structure.

Even when considering a sample with a low prevalence of dental caries, this experience had a negative impact on the quality of life of the child and the family, detected by the instrument of analysis. The importance of this perception can be felt by the fact that the parents of schoolchildren with a caries experience feel guilty because, at this age, children are dependent for the parents daily activities of oral hygiene. It is clear, therefore, that socioeconomic status and family structure may be significant predictors of children's OHRQOL ${ }^{12}$.

Of the schoolchildren evaluated in the present study, $63.7 \%$ presented some occlusal change. This prevalence was considered high when compared with the findings of other studies ${ }^{12,24}$ conducted in the same age group. However, malocclusion caused no impact on the quality of life of the child or his/her family, corroborating the results of previous studies ${ }^{24}$. The probable explanation for this is related to the stage of development and age group studied. In the stage of deciduous dentition, children still have no perception of the appearance of their teeth, which begins to be more important in the mixed dentition state, when the greater occlusal changes that affect the individual's self-image begin ${ }^{25-27}$. This did not exclude the importance of evaluating orthodontic treatment need at school-going age or of acting in a preventive manner in deciduous dentition.

Although this study had a cross-sectional design, which does not allow a causal relationship to be established, it was possible to understand the influence of contextual and clinical factors in the children's daily lives from different perspectives. Moreover, the present study reinforces the need for using subjective measures associated with clinical criteria, considering the opinions of children and their families in the elaboration of treatment strategies. Therefore, future studies of longitudinal designs are desirable to evaluate these effects over time. Another important aspect to consider is the extent to which public policies directed toward oral health are indispensable, as far as the promotion of better quality of life for the population is concerned. 
In conclusion, the child's family structure is affected by socioeconomic and clinical factors. low income and children with dental caries experience were negative aspects associated with OHRQoL in the children's family structure.

\section{References}

1. Feldens CA, dos Santos Dullius Al, Kramer PF, Scapini A, Busato AL, Vargas-Ferreira F. Impact of malocclusion and dentofacial anomalies on the prevalence and severity of dental caries among adolescents. Angle Orthod. 2015 Nov;85(6):1027-34. doi: 10.2319/100914-722.1.

2. Schuch HS, Costa FS, Torriani DD, Demarco FF, Goettems ML. Oral health-related quality of life of schoolchildren: impact of clinical and psychosocial variables. Int J Paediatr Dent. 2015 Sep;25(5):358-65. doi: 10.1111/ipd.12118.

3. Souza JGS, Martins AMEBL, Silveira MF, Jones KM, Meirelles MPMR. Impact of oral clinical problems on oral health-related quality of life in Brazilian children: a hierarchical approach. Int J Paediatr Dent. 2017 Jan;27(1):66-78. doi: 10.1111/ipd.12229.

4. Abanto J, Panico C, Bönecker M, Frazão P. Impact of demographic and clinical variables on the oral health-related quality of life among five-year-old children: a population-based study using self-reports. Int J Paediatr Dent. 2018 Jan;28(1):43-51. doi: 10.1111/ipd.12300.

5. Kumar S, Zimmer-Gembeck MJ, Kroon J, Lalloo R, Johnson NW. The role of parental rearing practices and family demographics on oral health-related quality of life in children. Qual Life Res. 2017 Aug;26(8):2229-36. doi: 10.1007/s11136-017-1568-7.

6. Carvalho AC, Paiva SM, Viegas CM, Scarpelli AC, Ferreira FM, Pordeus IA. Impact of Malocclusion on Oral Health-Related Quality of Life among Brazilian Preschool Children:a Population-Based Study. Braz Dent J. 2013 Nov-Dec;24(6):655-61. doi: 10.1590/0103-6440201302360.

7. Vedovello SAS, Ambrosano GM, Pereira AC, Valdrighi HC, Vedovello Filho M, Meneghim MC. Association between malocclusion and the contextual factors of quality of life and socioeconomic status. Am J Orthod Dentofacial Orthop. 2016 Jul;150(1):58-63. doi: 10.1016/j.ajodo.2015.12.022.

8. Gomes MC, Clementino MA, Pinto-Sarmento TC, Costa EM, Martins CC, Granville-Garcia AF, et al. Parental Perceptions of Oral Health Status in Preschool Children and Associated Factors. Braz Dent J. 2015 Jul-Aug;26(4):428-34. doi: 10.1590/0103-6440201300245.

9. Martins MT, Sardenberg F, Vale MP, Paiva SM, Pordeus IA. Dental caries and social factors: impact on quality of life in Brazilian children. Braz Oral Res 2015;29(1):1-7. doi: 10.1590/1807-3107BOR-2015.vol29.0133.

10. Sousa RV, Clementino MA, Gomes MC, Martins CC, Granville-Garcia AF, Paiva SM. Malocclusion and quality of life in Brazilian preschoolers. Eur J Oral Sci. 2014 Jun;122(3):223-9. doi: 10.1111/eos.12130.

11. Dimberg L, Arnrup K, Bondemark L. The impact of malocclusion on the quality of life among children and adolescents: a systematic review of quantitative studies. Eur J Orthod. 2015 Jun;37(3):238-47. doi: 10.1093/ejo/cju046.

12. Kumar S, Kroon J, Lalloo R. A systematic review of the impact of parental socio-economic status and home environment characteristics on children's oral health related quality of life. Health Qual Life Outcomes. 2014 Mar;21:12:41. doi: 10.1186/1477-7525-12-41.

13. Gomes MC, Neves ÉTB, Perazzo MF, Paiva SM, Ferreira FM, Granville-Garcia AF. Importance of contextual variables related to cavitated lesions in 5-year-old children. Int J Paediatr Dent. 2018 Mar;28:504-13. doi: 10.1186/1477-7525-12-41. 
14. Assaf AV, Tagliaferro EP, Meneghim MC, Tengan C, Pereira AC, Ambrosano GM, et al. A new approach for interexaminer reliability data analysis on dental caries calibration. J Appl Oral Sci. 2007 Dec;15(6):480-5.

15. Pahel BT, Rozier RG, Slade GD. Parental perceptions of children's oral health: the Early Childhood Oral Health Impact Scale (ECOHIS). Health Qual Life Outcomes. 2007 Jan;5:6. doi: 10.1186/1477-7525-5-6.

16. Martins-Júnior PA, Ramos-Jorge J, Paiva SM, Marques LS,Ramos-Jorge ML. Validations of the Brazilian version of the early childhood oral health impact scale (ECOHIS). Cad Saúde Pública. 2012 Feb;28(2):367-74.

17. World Health Organization. Oral health surveys, basics methods. Geneva: Word Health Organization; 1997.

18. Foster TD, Hamilton MC. Occlusion in the primary dentition: study of children at 2 and one-half to 3 years of age. Br Dent J 1969 Jan;126(2):76-9.

19. Grabowski R, Stahl F, Gaebel M, Kundt G. Relationship between occlusal findings and orofacial myofunctional status in primary and mixed dentition. Part I: prevalence of malocclusions. J Orofac Orthop. 2007 Jan;68(1):26-37.

20. Kumar S, Tadakamadla J, Zimmer-Gembeck MJ, Kroon J, Lalloo R, Johnson NW. Parenting practices and children's dental caries experience: A structural equation modelling approach. Community Dent Oral Epidemiol. 2017 Dec;45(6):552-8. doi: 10.1111/cdoe.12321.

21. Lai SHF, Wong MLW, Wong HM, McGrath CPJ, Yiu CKY. Factors influencing the oral health-related quality of life among children with severe early childhood caries in Hong Kong. Int J Dent Hyg. 2019 Nov;17(4):350-8. doi: 10.1111/idh.12414.

22. Chan $\mathrm{KL}$, Chen $\mathrm{M}$, Chen $\mathrm{Q}$, Ip P. Can family structure and social support reduce the impact of child victimization on health-related quality of life? Child Abuse Negl. 2017 Oct;72:66-74. doi: 10.1016/j.chiabu.2017.07.014

23. Nkansah-Amankra S, Luchok KJ, Hussey JR, Watkins K, Liu X. Effects of maternal stress on low birth weight and preterm birth outcomes across neighborhoods of South Carolina, 2000-2003. Matern Child Health J. 2010 Mar;14(2):215-26. doi: 10.1007/s10995-009-0447-4.

24. Perazzo MF, Gomes MC, Neves ET, Martins CC, Paiva SM, Costa EMMB, et al. Oral problems and quality of life of preschoold children: self-reports of children and perception of parents/caregivers. Eur J Oral Sci. 2017 Aug;125(4):272-9. doi: 10.1111/eos.12359.

25. Gomes MC, Clementino MA, Pinto-Sarmento TC, Costa EM, Martins CC, Granville-Garcia AF, et al. Parental Perceptions of Oral Health Status in Preschool Children and Associated Factors. Braz Dent J. 2015 Jul-Aug;26(4):428-3 doi: 10.1590/0103-6440201300245.

26. Gomes MC, Perazzo MF, Neves ÉT, Martins CC, Paiva SM, Granville-Garcia AF. Oral Problems and Self-Confidence in Preschool Children. Braz Dent J. 2017 Jul-Aug;28(4):523-30 doi: 10.1590/0103-6440201601295.

27. Gomes MC, Neves ÉTB, Perazzo MF, Paiva SM, Ferreira FM, Granville-Garcia AF. Contextual and individual determinants of oral health-related quality of life among five-year-old children: a multilevel analysis. Peer J. 2018 Aug;29:e5451. doi: 10.7717/peerj.54. 